\title{
Eleven years of retinopathy of prematurity in one neonatal intensive care unit in Jakarta, Indonesia
}

\author{
J Edy Siswanto, ${ }^{1}$ Nani H Widodo, ${ }^{2}$ Pieter J J Sauer ${ }^{3}$
}

'Department of Neonatology, Rumah Sakit Anak dan Bunda Harapan Kita (Harapan Kita Women and (hildren Hospital), West Jakarta, Indonesia ${ }^{2}$ Department of Opthalmology, Rumah Sakit Anak dan Bunda Harapan Kita (Harapan Kita Women and Children Hospital), West Jakarta, Indonesia ${ }^{3}$ Department of Pediatrics, Beatrix Children Hospital, Universitair Medisch, Groningen, The Netherlands

\section{Correspondence to}

Dr J Edy Siswanto, Department of Neonatology, Rumah Sakit Anak dan Bunda Harapan Kita, West Jakarta 11420, Indonesia; edyjo15@yahoo.com

Received 12 September 2017 Revised 18 February 2018 Accepted 21 February 2018 Published Online First 17 March 2018
Check for updates

To cite: Siswanto JE, Widodo NH, Sauer PJJ. Arch Dis Child

2018;103:619-621.

\section{ABSTRACT}

Background Retinopathy of prematurity (ROP) is a well-known complication in preterm infants. Data on the incidence of ROP in Indonesia, in relation to birth weight (BW) and gestational age (GA), are limited.

Objective To report the incidence of ROP in one of the oldest and largest neonatal intensive care unit (NICU) in Indonesia.

Methods We studied the incidence and severity of ROP in inborn infants with a BW of $\leq 1500 \mathrm{~g}$ and/or GA of $\leq 32$ weeks, who were admitted to the NICU of Harapan Kita Women and Children Hospital, Jakarta. In addition, infants with a higher $\mathrm{BW}$ and $\mathrm{GA}$, receiving more than $40 \%$ oxygen for a longer period, were screened.

Results In 2005-2015, 182 infants were born with a BW of $<1000 \mathrm{~g}$ and 437 with a weight of $1000-1500 \mathrm{~g}$. In the $<1000 \mathrm{~g}$ group, $27(46 \%)$ of the screened infants showed no ROP, 22 (37\%) showed ROP 1-2 and 10 (17\%) showed ROP 3-5. In the 1000-1500 g group, 172 $(68 \%)$ were without ROP, $71(28 \%)$ with ROP $1-2$ and nine (4\%) with ROP 3-5. Twenty-two (13\%) of the 163 screened infants weighing 1500-2000 g showed ROP $1-2$ and two (1.2\%) had ROP $3-5$. Eight (18\%) of the 44 screened infants born with a BW of more than $2000 \mathrm{~g}$ showed ROP 1-2 and none showed ROP 3-5.

Conclusion The total incidence of ROP as well as severe ROP in infants with a BW of $<1000 \mathrm{~g}$ and $1000-1500 \mathrm{~g}$ in our NICU is higher than in a developed country. ROP in Indonesia is also seen in infants with a BW of 1500-2500 g. Increasing the awareness of the risks of oxygen as well as better equipment to monitor oxygen delivery is essential.

\section{INTRODUCTION}

Retinopathy of prematurity (ROP) is a vision-threatening disease occurring in preterm infants related to an abnormal retinal vascular development. The disease can both regress and progress into blindness. The role of oxygen in the development of the disease is undisputed. ${ }^{1}$ The main risk factors for the development of this condition are gestational age (GA) and birth weight (BW). ${ }^{1}$ In developed countries, ROP is mainly seen in infants born after a GA of less than 28 weeks with a range of $16 \%-33 \%{ }^{1}$

The survival of preterm infants in low-income and middle-income countries has increased due to the introduction of neonatal intensive care centres. A relatively high rate of ROP is seen in both preterm survivors and in infants at higher GA. ${ }^{2-4}$

Indonesia is a country with a very rapid expansion of neonatal intensive care centres while facing financial limitations at the same time. One of the first neonatal intensive care units (NICUs) in Indonesia was founded in 1986 at Harapan Kita Hospital, Jakarta, with a capacity of 14-20 beds. We examined the incidence of ROP in the period of 2005-2015 in infants treated in this hospital to identify what could potentially occur in Indonesia after wide spread introduction of neonatal intensive care.

\section{METHODS}

All preterm infants with GA of $\leq 32$ weeks and birth weight (BW) of less than $1500 \mathrm{~g}$, admitted to the NICU of Harapan Kita Women and Children Hospital Jakarta Indonesia, in January 2005December 2015 were included. According to the hospital's policy, these infants were screened for ROP. We also included infants with a higher GA when screening for ROP, as our policy also require us to perform ROP screening in infants with GA higher than 32 weeks and BW higher than $1500 \mathrm{~g}$, when these infants are haemodynamically unstable and/or ventilated with more than $40 \%$ oxygen. GA was based on the mother's last menstrual period or the result of an ultrasound made during pregnancy. All infants were scored clinically using Ballard score. A single ophthalmologist performed all eye examinations using indirect ophthalmoscopy and scleral depression. Retcam examination was performed in a few patients to evaluate the progression of ROP. Indirect ophthalmoscopy was performed using 28 diopter lens. Mydriatic eye-drops were administered $30 \mathrm{~min}$ before examination. Time of first eye examination and follow-up examination was determined according to American Academic of Pediatrics (AAP) guidelines. ${ }^{5}$ Follow-up examinations were recommended by the ophthalmologist according to recommendations from the International Committee for the Classification of Retinopathy of Prematurity. ${ }^{6}$ All infants were followed-up until a stable retinal situation was reached. Informed consent was obtained from all parents.

\section{RESULTS}

In this 11-year period, 182 inborn infants with a $\mathrm{BW}$ of $<1000 \mathrm{~g}$ and 437 infants with a BW of 1000 $1500 \mathrm{~g}$ were admitted to our NICU. One hundred and eighty-five infants were born before 28 weeks and 569 between 28 and 32 weeks (table 1). In the $<1000$ g group, 27 (46\%) infants had no ROP, 22 (37\%) had ROP 1-2 and 10 (17\%) had ROP $3-5$. In the $1000-1500 \mathrm{~g}$ group, $172(68 \%)$ infants had no ROP, 71 (28\%) had ROP 1-2 and nine (4\%) had ROP 3-5. Annual incidence data are shown in table $2 a, b$.

Of the infants born $<28$ weeks, $28(60 \%)$ had no ROP, nine (19\%) had ROP 1-2 and 10 (21\%) 
Table 1 Clinical characteristics and the incidence of ROP of inborn infants admitted to neonatal intensive care unit in Harapan Kita Women and Children Hospital, 2005-2015

\begin{tabular}{|c|c|c|c|c|c|c|c|c|}
\hline BW (g)/GA (wks) & $<1000 \mathrm{~g}$ & $1000-1500 \mathrm{~g}$ & $>1500-2000 \mathrm{~g}$ & $>2000 \mathrm{~g}$ & $<28$ weeks & 28-32 weeks & $>32-34$ weeks & $>34$ weeks \\
\hline n (inborn) & 182 & 437 & 748 & 1618 & 185 & 569 & NA & NA \\
\hline GA (weeks) & $26-32$ & $26-35$ & $29-34$ & $32-40$ & & & & \\
\hline $\mathrm{BW}(\mathrm{g})$ & & & & & $529-1200$ & $676-2100$ & $700-2270$ & $1100-3175$ \\
\hline Died & 85 & 72 & - & - & 91 & 126 & - & - \\
\hline Screened & 59 & 252 & 163 & 44 & 47 & 261 & 156 & 107 \\
\hline Screened/survived (\%) & $61 \%$ & $69 \%$ & - & - & $48 \%$ & $59 \%$ & - & - \\
\hline $\mathrm{ROP}(-)$ & 27 & 172 & 139 & 36 & 28 & 187 & 126 & 91 \\
\hline ROP 1-2 & 22 & 71 & 22 & 8 & 9 & 66 & 29 & 13 \\
\hline ROP 3-5 & 10 & 9 & 2 & 0 & 10 & 8 & 1 & 3 \\
\hline Prevalence of any ROP (\%) & $54 \%$ & $32 \%$ & $15 \%$ & $18 \%$ & $40 \%$ & $29 \%$ & $19 \%$ & $15 \%$ \\
\hline Prevalence of severe ROP (\%) & $17 \%$ & $4 \%$ & $1 \%$ & $0 \%$ & $21 \%$ & $3 \%$ & $1 \%$ & $3 \%$ \\
\hline
\end{tabular}

n (inborn) GA $>32$ to $\leq 34$ weeks and $>34$ weeks not available.

$\mathrm{BW}$, birth weight; GA, gestational age; ROP, retinopathy of prematurity.

Table 2 Annual incidence of ROP in infants admitted to neonatal intensive care unit in Harapan Kita Women and Children Hospital, 2005-2015

\begin{tabular}{|c|c|c|c|c|c|c|c|c|c|c|c|c|c|}
\hline Year & 2005 & 2006 & 2007 & 2008 & 2009 & 2010 & 2011 & 2012 & 2013 & 2014 & 2015 & Total & Percentage \\
\hline \multicolumn{14}{|c|}{ (a) BW of $<1000 \mathrm{~g}$} \\
\hline Admitted & 13 & 20 & 15 & 12 & 13 & 8 & 15 & 12 & 24 & 21 & 29 & 182 & \\
\hline Died & 4 & 9 & 5 & 7 & 6 & 5 & 2 & 5 & 13 & 13 & 16 & 85 & $47 \%$ \\
\hline Screened & 2 & 7 & 2 & 5 & 3 & 3 & 5 & 4 & 11 & 8 & 9 & 59 & $61 \%$ \\
\hline $\operatorname{ROP}(-)$ & 1 & 3 & 1 & 3 & 0 & 1 & 2 & 1 & 5 & 4 & 6 & 27 & $46 \%$ \\
\hline ROP 1-2 & 0 & 2 & 0 & 2 & 3 & 2 & 1 & 2 & 5 & 3 & 2 & 22 & $37 \%$ \\
\hline ROP 3-5 & 1 & 2 & 1 & 0 & 0 & 0 & 2 & 1 & 1 & 1 & 1 & 10 & $17 \%$ \\
\hline \multicolumn{14}{|c|}{ (b) BW of $1000-1500 \mathrm{~g}$} \\
\hline Admitted & 37 & 31 & 32 & 22 & 44 & 33 & 27 & 33 & 50 & 47 & 81 & 437 & \\
\hline Died & 14 & 5 & 1 & 3 & 9 & 3 & 6 & 4 & 3 & 10 & 14 & 72 & $16 \%$ \\
\hline Screened & 10 & 14 & 17 & 16 & 32 & 22 & 21 & 16 & 23 & 37 & 44 & 252 & $69 \%$ \\
\hline $\operatorname{ROP}(-)$ & 5 & 12 & 14 & 12 & 20 & 17 & 9 & 13 & 11 & 20 & 39 & 172 & $68 \%$ \\
\hline ROP 1-2 & 5 & 1 & 3 & 4 & 11 & 2 & 12 & 3 & 11 & 14 & 5 & 71 & $28 \%$ \\
\hline ROP 3-5 & 0 & 1 & 0 & 0 & 1 & 3 & 0 & 0 & 1 & 3 & 0 & 9 & $4 \%$ \\
\hline
\end{tabular}

$\mathrm{BW}$, birth weight; ROP, retinopathy of prematurity.

had ROP 3-5. Of the infants born after 28-32 weeks, 187 (72\%) showed no ROP, 66 (25\%) showed ROP 1-2 and eight

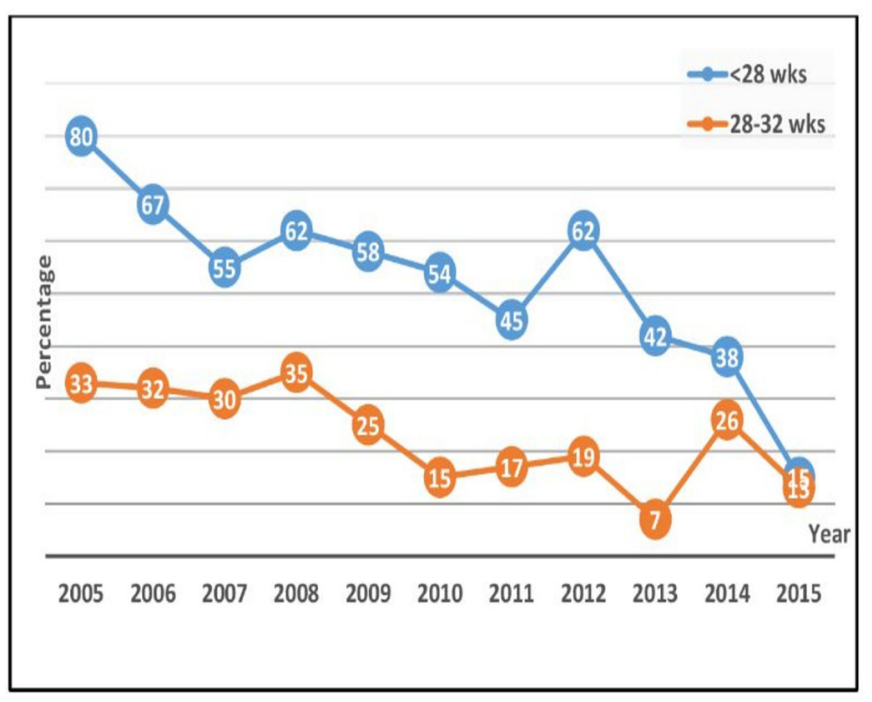

Figure 1 Mortality of infants born after $<28$ and $28-32$ weeks in neonatal intensive care unit in Harapan Kita Women and Children Hospital, Indonesia, 2005-2015.
(3\%) showed ROP 3-5. The number of admitted infants in both groups increased over time, while the mortality showed a decrease (figure 1). The percentage of infants with severe ROP seemed to decrease over time (table $3 \mathrm{a}, \mathrm{b})$.

In this 11 years' period, 156 infants born between 32 and 34 weeks and 107 born after 34 weeks were screened for ROP. Twenty-nine of the infants born between 32 and 34 weeks showed ROP 1-2 and one infant had ROP 3-5. Thirteen of the infants born after 34 weeks showed ROP $1-2$ and three infants showed ROP 3-5.

\section{DISCUSSION}

When we compare the incidence of ROP during the last 3 years in our NICU with data from developed countries, we see that the incidence in our unit is higher compared with that in developed countries. Forty per cent of infants with a GA of $<28$ weeks had ROP of all stages and $21 \%$ showed ROP $>3$. More concerning is the incidence of ROP in our patients with a GA of 28-32 weeks where any stage ROP was found in $29 \%$, and ROP $>3$ in $3 \%$ of the screened infants. Finally, ROP was also observed in infants with a GA of $>32$ weeks or a BW of $>1500 \mathrm{~g}$.

The incidence of ROP in our unit is comparable with data from other developing countries, as presented recently in a review by Zin and Gole. ${ }^{2}$ Severe ROP was found in infants with a BW of $<1500 \mathrm{~g}$ 
Table 3 Annual incidence of ROP in infants admitted to neonatal intensive care unit in Harapan Kita Women and Children Hospital, 2005-2015

\begin{tabular}{|c|c|c|c|c|c|c|c|c|c|c|c|c|c|}
\hline Year & 2005 & 2006 & 2007 & 2008 & 2009 & 2010 & 2011 & 2012 & 2013 & 2014 & 2015 & Total & Percentage \\
\hline \multicolumn{14}{|c|}{ (a) Born at GA of $<28$ weeks } \\
\hline Admitted & 12 & 12 & 22 & 18 & 15 & 9 & 11 & 15 & 10 & 21 & 40 & 185 & \\
\hline Died & 10 & 8 & 12 & 11 & 9 & 5 & 5 & 9 & 4 & 8 & 6 & 87 & $47 \%$ \\
\hline Screened & 2 & 4 & 3 & 2 & 2 & 4 & 3 & 5 & 6 & 6 & 10 & 47 & $48 \%$ \\
\hline $\operatorname{ROP}(-)$ & 1 & 2 & 1 & 1 & 0 & 2 & 2 & 3 & 5 & 4 & 7 & 28 & $60 \%$ \\
\hline ROP 1-2 & 0 & 0 & 1 & 1 & 1 & 2 & 0 & 1 & 0 & 1 & 2 & 9 & $19 \%$ \\
\hline ROP 3-5 & 1 & 2 & 1 & 0 & 1 & 0 & 1 & 1 & 1 & 1 & 1 & 10 & $21 \%$ \\
\hline
\end{tabular}

\begin{tabular}{|c|c|c|c|c|c|c|c|c|c|c|c|c|c|}
\hline \multicolumn{14}{|c|}{ (b) Born at GA between 28 and 32 weeks } \\
\hline Admitted & 32 & 38 & 50 & 45 & 51 & 44 & 30 & 55 & 60 & 65 & 99 & 569 & \\
\hline Died & 12 & 12 & 15 & 16 & 13 & 7 & 5 & 10 & 6 & 17 & 13 & 126 & $22 \%$ \\
\hline Screened & 13 & 22 & 20 & 9 & 27 & 26 & 27 & 16 & 21 & 36 & 44 & 261 & $59 \%$ \\
\hline ROP (-) & 9 & 18 & 19 & 7 & 17 & 20 & 15 & 12 & 10 & 22 & 38 & 187 & $72 \%$ \\
\hline ROP 1-2 & 4 & 3 & 1 & 2 & 9 & 3 & 11 & 4 & 10 & 13 & 6 & 66 & $25 \%$ \\
\hline ROP 3-5 & 0 & 1 & 0 & 0 & 1 & 3 & 1 & 0 & 1 & 1 & 0 & 8 & $3 \%$ \\
\hline
\end{tabular}

BW, birth weight; ROP, retinopathy of prematurity.

and/or a GA of $<32$ weeks ranging from $20.6 \%$ in Pakistan to $5.9 \%$ in Brazil. Our data showed that $6 \%$ of all screened infants of BW below $1500 \mathrm{~g}$ and/or a GA of $\leq 32$ weeks fit well in this range. Blencowe et al estimated the incidence of all stage of ROP in infants $<32$ weeks in developing countries as $36.5 \% .^{3}$ The incidence, however, is very dependent on both the infant mortality rate (IMR) and neonatal mortality rate (NMR) in each country and the mortality in the NICU. The IMR is a reflection of the level of access to and the quality of healthcare and the level of socioeconomic development. The higher the IMR and NMR, the higher the incidence of ROP. The higher neonatal mortality might also cause underestimation of the incidence of ROP. The mortality rate of infants $<32$ weeks admitted to our NICU in the past few years is not much higher compared with developed countries. The incidence of ROP is higher. Our data on the incidence of ROP might be an underestimation of the real incidence of ROP given the higher mortality in our total cohort.

It is not clear which factor might be responsible for the higher incidence of severe ROP in developing countries like Indonesia compared with developed countries. Gilbert reported a correlation between the incidence of ROP and the IMR, ${ }^{7}$ indicating that a lack of resources might be involved. The most likely explanation for the higher incidence of ROP in our NICU is a less strict control of oxygen delivery.

One limitation of this study is the relatively small size of infants subjects studied. However, our unit is one of the largest NICUs in Indonesia. Combining data from different centres with potentially different modes of ROP screening also would not increase the reliability of the data. Therefore, we present only the data obtained in our centre, which might be representative of the current situation in our country. Another limitation is that not all infants were screened. When the one ophthalmologist who did all the screening was not available, no other experienced ophthalmologist could conduct the screening. Second, not all infants in the first period of the study were screened, a strict protocol was introduced in 2009. Finally, some infants were considered too unstable to investigate. We do not believe that the missing infants caused a bias in the results.

\section{CONCLUSION}

The incidence of ROP in infants with a GA of $<28$ weeks and 28-32 weeks and a BW of $<1000 \mathrm{~g}$ and 1000-1500g in our
NICU is higher than in developed countries. A higher incidence of severe ROP was also observed. ROP was also seen in infants with a BW of $1500-2500 \mathrm{~g}$ born at a GA of $>32$ weeks. A stricter control of oxygen delivery in preterm infants in Indonesia is needed to reduce the incidence of ROP. Increasing the awareness of oxygen as well as better equipment to monitor oxygen delivery in Indonesia is essential.

Contributors JES is the person who wrote the first draft of this manuscript and involved directly in whole aspects of this research/manuscript. NWH contributed to the interpretation and discussions in ophthalmology. PJJS assisted in literature review, wrote the report and wrote the discussion section.

Funding The authors have not declared a specific grant for this research from any funding agency in the public, commercial or not-for-profit sectors.

Competing interests None declared.

Patient consent Detail has been removed from this case description/these case descriptions to ensure anonymity. The editors and reviewers have seen the detailed information available and are satisfied that the information backs up the case the authors are making.

Ethics approval International Review Board of University of Indonesia School of Public Health.

Provenance and peer review Not commissioned; externally peer reviewed.

(c) Article author(s) (or their employer(s) unless otherwise stated in the text of the article) 2018. All rights reserved. No commercial use is permitted unless otherwise expressly granted.

\section{REFERENCES}

1 Hellström A, Smith LE, Dammann O. Retinopathy of prematurity. Lancet 2013:382:1445-57.

2 Zin A, Gole GA. Retinopathy of prematurity-incidence today. Clin Perinatol 2013:40:185-200.

3 Blencowe H, Lawn JE, Vazquez T, et al. Preterm-associated visual impairment and estimates of retinopathy of prematurity at regional and global levels for 2010. Pediatr Res 2013;74(Suppl 1):35-49.

4 Edy Siswanto J, Sauer PJ. Retinopathy of prematurity in Indonesia: incidence and risk factors. J Neonatal Perinatal Med 2017;10:85-90.

5 Section on Ophthalmology American Academy of Pediatrics, American Academy of Ophthalmology, American Association for Pediatric Ophthalmology and Strabismus. Screening examination of premature infants for retinopathy of prematurity. Pediatrics 2006;117:572-6. Erratum in: Pediatrics. 2006;118(3):1324.

6 International Committee for the Classification of Retinopathy of Prematurity. The international classification of retinopathy of prematurity revisited. Arch Ophthalmol 2005;123:991-9.

7 Gilbert C, Fielder A, Gordillo L, et al. Characteristics of infants with severe retinopathy of prematurity in countries with low, moderate, and high levels of development: implications for screening programs. Pediatrics 2005;115:e518-e525. 